\title{
MECHANISM OF SOLANUM BETACEUM TO PREVENT MEMORY IMPAIRMENT IN CIGARETTE SMOKE-EXPOSED RAT
}

\author{
SITI KHAERUNNISA ${ }^{1 *}$, KURNIA KUSUMASTUTI ${ }^{2}$, ARIFA MUSTIKA ${ }^{3}$, NANIK SITI AMINAH ${ }^{4}$, \\ SUHARTATI SUHARTATI ${ }^{5}$
}

${ }^{1}$ Departement of Medical Biochemistry, Faculty of Medicine, Universitas Airlangga, Indonesia. ${ }^{2}$ Departement of Neurology, Universitas Airlangga -Dr. Soetomo Hospital, Indonesia. ${ }^{3}$ Departement of Medical Pharmacology, Faculty of Medicine, Universitas Airlangga, Indonesia. ${ }^{4}$ Departement of Chemistry, Faculty of Medicine, Universitas Airlangga, Indonesia. ${ }^{5}$ Departement of Medical Biochemistry, Universitas Wijaya Kusuma, Indonesia. Email: st.khaerunnisa@fk.unair.ac.id

Received: 03 July 2018, Revised: 18 July 2018, Accepted: 22 November 2018

ABSTRACT

Objective: The aim of this study was conducted to evaluate the neuroprotective role of Solanum betaceum against memory impairment due to chronic cigarette smoke exposure in rat brain.

Methods: Adult male albino rats were exposed to cigarette smoke for 28 days, 3 pc cigarette/day, and simultaneously administered with S. betaceum in Groups K2, K3, and K4 (100 mg/kg b.w/day, $200 \mathrm{mg} / \mathrm{kg}$ b.w/day, and $400 \mathrm{mg} / \mathrm{kg}$ b.w/day), respectively. The level of N-methyl-D-aspartate (NMDA), c-AMP response element binding (CREB) protein, brain-derived neurotrophic factor (BDNF), number of neuron and glial cells, and memory was also measured.

Results: S. betaceum administration could prevent from memory impairment significantly $(\mathrm{p}<0.05)$ by decreased time to reach the target at $\mathrm{Y}$-Maze and maintained the levels of CREB, BDNF, neuron, and glial cells (microglia, astrocytes, and oligodendrocytes) significantly ( $p<0.05$ ) but did not significantly decreased NMDA levels ( $\mathrm{p}>0.05)$.

Conclusion: Exposure to cigarette smoke compromised the memory functions. The result of this study shown that administration of S.betaceum could inhibit memory impairment and inhibit the decrease of neuron cells, increase the level of BDNF and number of glia cells including microglia, astrocytes and oligodendrocytes. The mechanism of $S$. betaceum to prevent memory impairment through activation of CREB (the transcription factor) which further enhances the formation of BDNF (the neurotrophic factors), thus increase activation of the glia cells to protect brain cell damage, thus preventing memory impairment due to cigarette smoke exposure.

Keywords: Solanum betaceum, N-methyl-D-aspartate, c-AMP response element binding, Brain-derived neurothropic factor, Neuron, Glia, Memory

(c) 2019 The Authors. Published by Innovare Academic Sciences Pvt Ltd. This is an open access article under the CC BY license (http://creativecommons. org/licenses/by/4. 0/) DOI: http://dx.doi.org/10.22159/ijap.2019.v11s3.M1024

\section{INTRODUCTION}

Memory impairment is the first symptom of dementia [1]. The causes of memory impairment are dentate gyrus cells death, decreased elasticity of blood vessels [2], heavy metal toxicity [3], and exposure to cigarette smoke [4-8]. Chen et al. [9] said that participants exposed to cigarette smoke shown an increased risk of dementia. Another study has shown that passive smokers lose about $20 \%$ of remembering ability in memory tests and increase the risk of dementia in the elderly population which not diagnosed with cardiovascular disease [10]. A number of animal research studies have shown that rat exposed to cigarette smoke showed memory decrease and histologic changes in the brain [6-8].

Solanum betaceum (tamarillo) is a plant from Solanaceae family which is abundant in Indonesia. Several studies have been reported that $S$. betaceum has a high antioxidant phytochemical component, for example, anthocyanin and flavonols, phenolic acids, and carotenoids $[11,12]$. Our previous study shown that screening of $S$. betaceum consists of flavonoid, tannin, gallic tannin, and terpenoid. A number of epidemiological study and interventional facts in humans and animals shown that tannins have the inverse effect on neurodegenerative disease progression and age-related neurocognitive disorders [13]. Terpenoid has been reported to have beneficial effects on spatial learning and cognitive function through increased synaptic density in the brain [14]. Flavonoids can improve memory and cognition function through two paths, direct and indirect $[15,16]$. This study was conducted to analyze the mechanism of $S$. betaceum as protective effect in memory impairment due to cigarette smoke exposure.

\section{METHODS}

\section{Chemicals and reagents}

Level of N-methyl-D-aspartate (NMDA), c-AMP response element binding (CREB), and brain-derived neurothropic factor (BDNF) was obtained from Bioassay Technology Laboratory, Shanghai, China, with Cat No.E0999Ra, Cat No. E0039Ra, and Cat No.E0476Ra, respectively. All other chemicals and reagents were used of reagent grade and highest purity. S. betaceum was purchased from farmland in Wonosobo, Central Java, Indonesia, and identified from Indonesian Institute of Science (LIPI). Locally available brand of cigarette, manufactured in Surabaya, East Java, Indonesia, was used in this study.

\section{Experimental design}

This experimental design used male albino rats (3 months, 180-200 g) in a health condition and was divided into five groups. The rats were received with standard pelleted rat feed and water ad libitum. They were acclimatized to the laboratory conditions and maintained under $12 \mathrm{~h}$ light and dark cycles at room temperature. Group $\mathrm{K}_{0}$ (negative control), Group $\mathrm{K}_{1}$ : Positive control and smoke exposure, Group $\mathrm{K}_{2}$ : Smoke exposure and ethanol extract of $S$. betaceum $100 \mathrm{mg} / \mathrm{BW}$ [17], Group $\mathrm{K}_{3}$ : Smoke exposure and ethanol extract of $S$. betaceum $200 \mathrm{mg} / \mathrm{kg} \mathrm{BW} \mathrm{[17],}$ and Group $\mathrm{K}_{4}$ : Smoke exposure and ethanol extract of $S$. betaceum $400 \mathrm{mg} / \mathrm{kg} \mathrm{BW}$ [17]. The experiments were carried out in accordance with the guidelines of ethical clearance provided by the Animal Care and Use Committee, Veterinary Faculty of Airlangga University with certificate No.741-KE. 
Preparation of $S$. betaceum's ethanol extract

$S$. betaceum was dried by fresh dryer. Dry powder was extracted by maceration using ethanol solvent for $3 \times 24 \mathrm{~h} 3$ times atroom temperature and then separated between filtrate and residue. The ethanol extract was filtered and evaporated with a rotary vacuum evaporator to obtain a viscous extract. The ethanol extract of $S$. betaceum was added to the treatment diet in the form of a suspension using 1\% CMC with a dose of $2 \mathrm{ml} / 200 \mathrm{~g}$ b.w. $S$. betaceum extract was simultaneously administered to the treatment group before exposure to cigarette smoke during the experiment.

\section{Cigarette smoke exposure}

Exposure of cigarette smoke in experimental animals was given to Groups K1, K2, K3, and K4 by 3 pc cigarettes per day for 28 days, at 06.00 p.m. The exposure system consisted of a glass box with two holes: Several holes to insert cigarette smoke and other holes to remove cigarette smoke. A $50 \mathrm{cc}$ syringe is pulled out to suck the cigarette placed on the iron pipe, so the cigarette smoke entered the syringe. The process of pumping $50 \mathrm{cc}$ syringe is done repeatedly until the cigarette burned out.

\section{Consolidation training and memory test (Y-Maze)}

Y-maze is a labyrinth which consists of two roads, right and left. On one road (right or left) of the labyrinth was placed a gift such as food which indicated the end point of the Rat to reach the finish. Rats must made a choice of roads to take. The rats were guided manually when it could not reach the target within $90 \mathrm{~s}$. The latent time of achieving the target during the exercise was measured. Rats must learn not to go back into the aisle where the food has been taken. Re-entry was considered an error. During the training period, a number of symbols were attached to several sides near the Y Maze to guide the rats to reach the finish point. The memory test was performed on the last day and all symbols that used to guide the rat were removed. The frequency of reaching targets and settling time in the area was calculated based on the recording. The memory test was expressed in seconds as the time required for rat to reach the target. Rat with less time indicates that it has a good memory.

\section{Laboratory examination}

\section{Determining of neuron cells and glial cells}

Determining a number of neuron and glial cells (e.g., microglia, astrocytes, and oligodendrocytes) by counting the number of neuron and glial cells (e.g., microglia, astrocytes, and oligodendrocytes) from hippocampus tissue using Hematoxylin-Eosin staining and viewed with a $\times 400$ magnification microscope and five fields. Presentation of neuron and glial cells is shown in Fig. 1 .

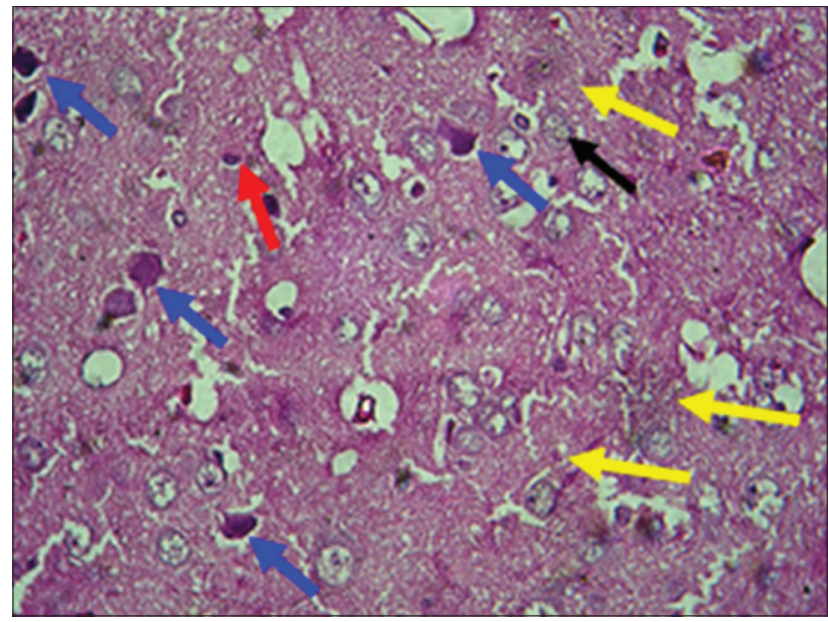

Fig. 1: Hippocampus tissue with Hematoxylin-Eosin staining (blue=neuron, red=microglia, yellow=astrocyte, black= oligodendrocyte)

\section{Determining level of CREB, NMDA, and BDNF}

The fixed hippocampus of the left or right hemisphere was analyzed using the enzyme-linked immunosorbent assay (ELISA) method. The fixed hippocampus was homogenized using a sonicator with added buffer lysis and then centrifuged at $15000 \times \mathrm{g}$ for $15 \mathrm{~min}$ at $4^{\circ} \mathrm{C}$, and the supernatant was used for the analysis. Samples were stored at $-20^{\circ} \mathrm{C}$. The level of CREB, NMDA, and BDNF in the hippocampus was used to determine using the ELISA test.

\section{Statistical analysis}

The statistical analysis was performed by one-way ANOVA and KruskalWallis test. The statistical significance between the experimental groups was assessed by least significant difference and Mann-Whitney U-test with $\mathrm{p}<0.05$. Data analysis was used SPSS ver.23.

\section{RESULTS AND DISCUSSION}

The level of CREB, BDNF, and oligodendrocytes in hippocampus and memory of control and experimental animals are summarized in Table 1. A significant decrease $(\mathrm{p}<0.05)$ in the level of CREB and BDNF and an increase time $(\mathrm{p}<0.05)$ in memory test were observed in Group K1 rats exposed to cigarette smoke compared to Group K0 rats. S. betaceum per administered Group K2, K3, and K4 rats showed a significant ( $<<0.05$ ) increase in their level of CREB, BDNF, and oligodendrocytes and decrease time in memory test compared to Group K1 rats which show the protective effect of memory impairment by $S$. betaceum.

Table 2 shows the number of neuron and glial cells in hippocampus of control and experimental animals. The level of NMDA did not show any differences between groups $(\mathrm{p}>0.05)$. Group $\mathrm{K} 1$ rats exposed to cigarette smoke showed a significant decrease $(p<0.05)$ in a number of microglia and astrocyte cells when compared to control rats. A significant increase $(\mathrm{p}<0.05)$ in the number of neuron was observed in Group K2, K3, and K4 rats, a significant increase $(\mathrm{p}<0.05)$ in the number of microglia was observed in Group K3 and K4 rats, and a significant increase $(\mathrm{p}<0.05)$ in the number of astrocyte was observed in Group K3 rats when compared to Group K1 rats.

The present study shown that cigarette smoke exposure could decrease some factors which involve in memory formation, for example, CREB, BDNF, and microglia and astrocytes, and thus, it could decrease memory. Fig. 2 shows mechanism of memory impairment due to cigarette smoke exposure. Cigarette contains three toxic substances, i.e. carbon monoxide, nicotine, and tar. Nicotine in cigarette smoke has been shown to inhibit the expression of zone occludin- 1 which is a potential protein in tight junction and also has a negative effect on the blood vessels and the $\mathrm{Na}+\mathrm{K}+2 \mathrm{Cl}$ - co-transporter from the brain to the blood, which can damage blood-brain barrier (BBB) function. Tar can induce the formation of reactive oxygen species (ROS) to trigger oxidative stress. Carbon monoxide in cigarette smoke tends to bind easily to hemoglobin so that can be reduced level of oxygen in the blood. The effects of these three toxic compounds result in overproduction of glutamate in the hippocampus, leading to increased overactivation of NMDA receptors and excessive increase of calcium $\left(\mathrm{Ca}^{2+}\right)$ influx. Overproduction of $\mathrm{Ca}^{2+}$ can be causing negative effects of excitotoxicity that leads to inhibit biosignaling pathways, for example, calcium/calmodulin-dependent protein kinase type II (CaMKII), CREB, and BDNF which are factors involved in memory formation. Inhibition of CREB and BDNF is related to the number of neuron cells and glial cells in the hippocampus. Hippocampus is part of the limbic system that plays an important role in short-term memory and plays a role in consolidation into long-term memory $[4,5,18-20]$.

Previous studies revealed that prolonged cigarette smoke exposure associated with abnormality of brain function [4,5] including cognition function disorder for instance ability of decision-making, impulse controlling, judgment, planning, and reasoning. It is related to changing of brain reward system [4]. Deficiency of executive 
Table 1: Mean and standard deviation of CREB, BDNF, oligodendrocytes, and memory of rats in control and experiment group

\begin{tabular}{|c|c|c|c|c|c|c|c|}
\hline \multirow[t]{2}{*}{ Variable } & \multicolumn{5}{|l|}{ Group $^{\#}$} & \multirow[t]{2}{*}{ SI } & \multirow[t]{2}{*}{ ANOVA } \\
\hline & KO & K1 & K2 & K3 & K4 & & \\
\hline CREB & $13.75 \pm 0.85^{\mathrm{a}}$ & $10.18 \pm 2.60^{b}$ & $13.94 \pm 1.31^{\mathrm{a}}$ & $14.25 \pm 1.29^{\mathrm{a}}$ & $14.29 \pm 0.88^{\mathrm{a}}$ & $\mathrm{ng} / \mathrm{ml}$ & $0.000 *$ \\
\hline Oligodendrocytes & $11.37 \pm 3.10^{\mathrm{acb}}$ & $10.17 \pm 1.69^{b}$ & $14.31 \pm 3.51^{\mathrm{a}}$ & $14.94 \pm 3.85^{\text {acd }}$ & $13.94 \pm 2.58^{\mathrm{ac}}$ & - & $0.026^{*}$ \\
\hline Memory & $14.71 \pm 2.17^{\mathrm{a}}$ & $23 \pm 4.74^{\mathrm{b}}$ & $13.14 \pm 3.81^{\mathrm{ac}}$ & $15.52 \pm 4.06^{\mathrm{a}}$ & $18.05 \pm 2.23^{\mathrm{ad}}$ & $\mathrm{s}$ & $0.000^{*}$ \\
\hline
\end{tabular}

${ }^{*}=$ Significantly with $\mathrm{p}<0.05,{ }^{*}=$ Mean \pm SD, ${ }^{\mathrm{a}, \mathrm{b}, \mathrm{c}, \mathrm{d}}=$ Different superscript means significant between groups, CREB: c-AMP response element binding, BDNF: Brain-derived neurothropic factor

Table 2: Mean and median of NMDA, neuron, microglia, and astrocytes of rats in control and experiment group

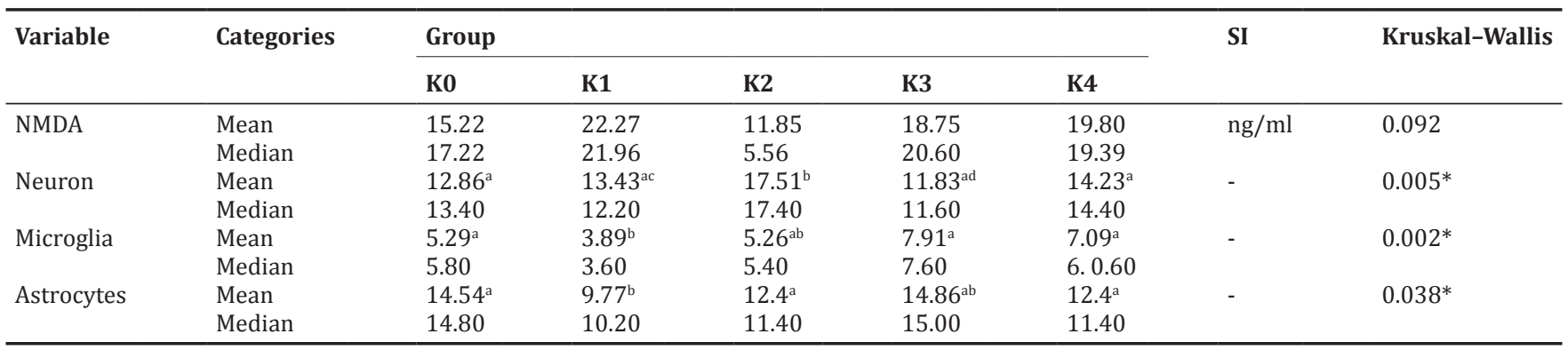

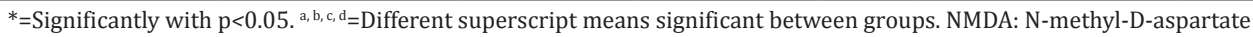

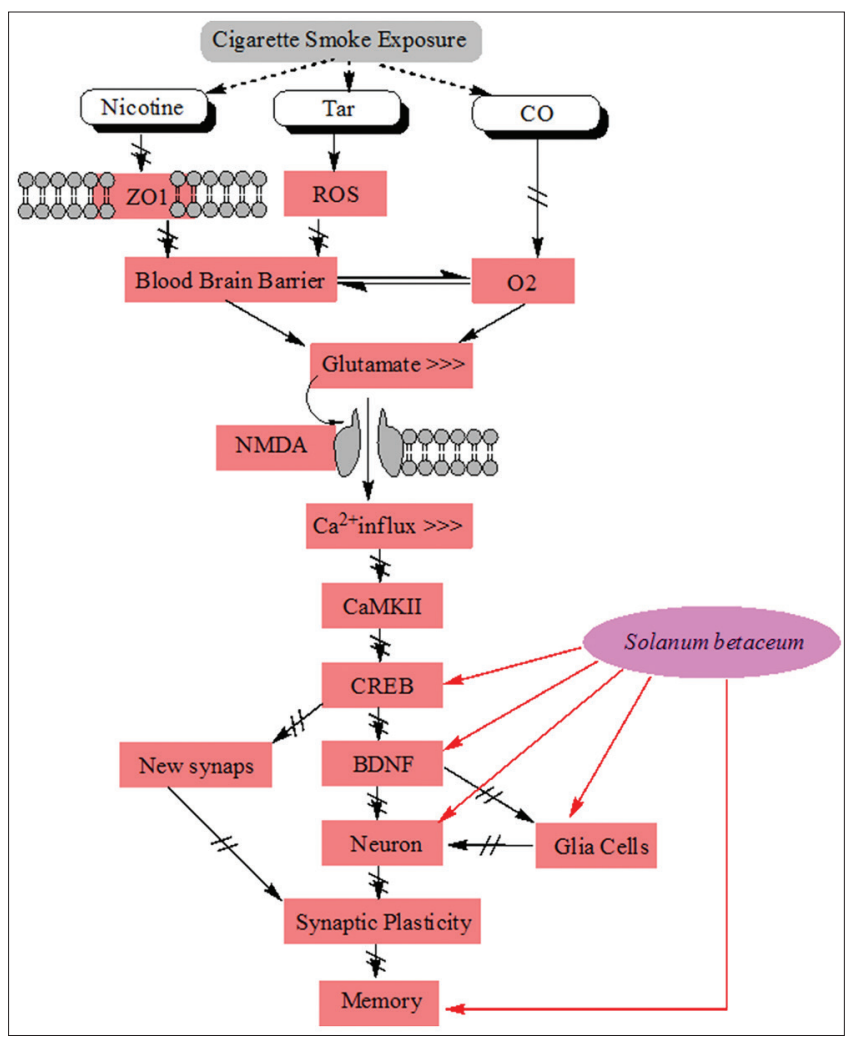

Fig. 2: Mechanism of memory impairment due to cigarette smoke exposure and neuroprotective role of Solanum betaceum to prevent memory impairment. $\cdots=$ consist of $\rightarrow \rightarrow=$ inhibit

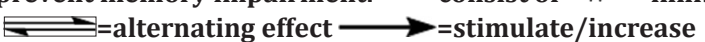

function, cognition flexibility, fine intelligence, rate of learning process, memory, and working memory could be found in chronic cigarette smokers. They suffered a brain atrophy and aberrant in anterior frontal area, subcortical nucleus, and commissural white matter. However, underlying mechanism of negative effect of cigarette smoke on human nervous system is still unclear [4].
Our study disclosed that ethanol extract of $S$. betaceum on cigarette smoke-exposured rats could prevent memory impairment and increased level of BDNF and CREB and inhibited decreasing neuron and glial cells (microglia, astrocyte, and oligodendrocyte) in hippocampus and enhance memory function (Fig. 2). Phytochemistry screening analysis in this research informed that ethanol extract of $S$. betaceum contained flavonoid, tannin, gallic tannin, and terpenoid.

Based on literatures, the ethanol extract of $S$. betaceum consisted of abundance polyphenol with the form of flavonoid which could improve learning and memory [15-21]. Flavonoid influenced memory and cognition in two mechanisms: Indirect mechanism through endothelial of peripheral blood vessel and direct mechanism through BBB [15]. Indirect signals activated eNOS and inhibited NADPH oxidase which trigered incresing of nitric oxide (NO). NO would response neural activation on NMDA receptor, glutamate signaling, and diffusion of arterial and capillary vessels which conducted increase brain blood flow. Molecular mechanism involved in those was $\mathrm{Ca}^{2+}$ dependent, signaling of cyclic guanosine monophosphate, or protein kinase B (Akt) PKB) and thus enhanced oxygen demands and nutrient [16]. Direct mechanism of flavonoid as neuroprotecive could pass BBB and then activate extracellular signal-regulated kinase-CREB (ERK-CREB), BDNF, Akt/PKB, and mammalian target of rapamycin protein- the activityregulated cytoskeletal (mTOR-Arc) which would modify synapse function and synaptic brain plasticity, and then improve memory and cognition function [16].

Astrocyte and microglia have a pivotal role, homeostatic, detoxification, and immunity response on chemistry material, infection, and traumatic injuries [22]. Microglia have a role function as part of neuron supporting system. Microglia are macrophage of the central nervous system. Stimulation on microglia induces several kinds of mediators such as NO and tumor necrosis factor alpha (TNF $\alpha$ ) [23]. Astrocyte and microglia increment indicates an inflammation. Activation of glia cell including microglia and astrocytes associated with neurodegenerative disease. Nevertheless, microglia have a potential mechanism to downregulate activate cells including deactivation and elimination of the cells in brain [23]. Prior studies proved that activation of microglia and astrocyte became apoptosis to activate themselves which are similar to activation-induced cell death (AICD) in lymphocytes. Apoptosis autoregulation of neuroglia was autocrine NO dependent [23]. 


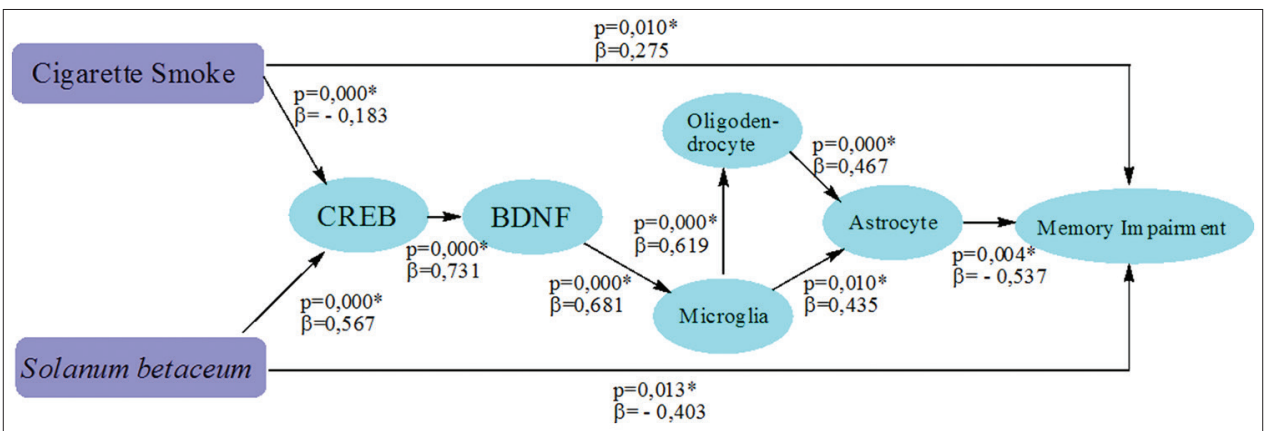

Fig. 3: Path analysis of direct effect Solanum betaceum to prevent memory impairment due to cigarette smoke exposure. ${ }^{*}=$ significant with $\mathbf{p}<0.05, \beta$ value shows positive or negative correlation coefficient

Flavonoid baicalein was reported that it could regulate AICD on brain microglia [23].

Flavonoid was reported that it could stimulate astrocyte and microglia, which had the ability to regulate TNF- $\alpha$ and to eliminate NO on primary glia cell cultured [22]. Previuos study showed that flavonoid has a neuroprotective effect on oxidative stress and prevents neuron cell death [15,24]. Cytokines such as interleukin $1 \beta$ (IL1 $\beta$ ) could trigger neuron and glial cells death. Interleukin $1 \beta$ and TNFa may induce activation of inducible nitric oxide synthase (iNOS), nitric oxide (NO*) and NADPH oxidase [15]. Flavonoid of blueberry was told that it reduced ther production of NO*, IL-1 $\beta$, and TNF-a which were activated by maicroglia, whereas flavonol quercetin, catechin, wogonin, baicalein, epigallocatechin, and genistein could regulate microglia and astrocyte which were mediated by neuroinflammation through (1) iNOS and cyclooxygenase-2 expression, (2) NO* production, and (3) cytokine release, NADPH oxidase activation, which then generates ROS in astrocyte and microglia. All appearance effects initiated signaling of protein and lipid kinase directly, i.e., MAPK signaling cascade which regulates iNOS and TNF- $\alpha$ on glial cells [15]. Several epidemiologic and intervention facts on human or animal stated that tannin had an inverse effect in neurodegenerative disease [13]. Terpenoid has been reported which had a beneficial effect on spatial learning and cognitive function throughout increment of brain synaptic [14].

Figure 3 shown the mechanism of $S$. betaceum to prevent memory impairment due to cigarette smoke exposure. The significant of direct mechanism consist of $S$. betaceum to CREB, cigarette smoke exposure to CREB, CREB to BDNF, BDNF to microglia, microglia to oligodendrocytes, microglia to astrocytes, oligodendrocytes to astrocytes, and astrocytes to memory. Other pathways including $S$. betaceum to NMDA, NMDA to CREB, NMDA to BDNF, BDNF to neuron, and neuron to microglia, which have no direct effect.

\section{CONCLUSION}

The present study findings show that chronic cigarette smoking induces memory impairment and hippocampus profile changes on the brain. S. betaceum ameliorates cigarette smoking-induced memory impairment probably through its neuroprotective effect on biosignaling on memory formation, for example, CREB, BDNF and $\sum$ neuron cells, and $\sum$ glia (microglia, astrocyte, and oligodendrocyte) in the hippocampus. Thus, the results of our investigation suggest that $S$. betaceum can be a potent neuroprotective role in the brain and hence may have useful properties as a natural neuroprotective supplement, capable of preventing memory impairment. The mechanism of $S$. betaceum to prevent memory impairment was through the activation of CREB as a transcription factor which further enhances the formation of neurotrophic factors, for example, BDNF. Thus, BDNF has a positive correlation with the activation of glial cell to prevent brain cell damage, so it could prevent memory impairment due to cigarette smoke exposure (Fig. 3). However, further studies pertaining to the phytochemical compounds involve of action of $S$. betaceum which are warranted.

\section{CONFLICTS OF INTEREST}

The authors declare that we have no conflicts of interest.

\section{ACKNOWLEDGMENT}

This research was supported by Universitas Airlangga, Surabaya, East Java, Indonesia, and Lembaga Pengelola Dana Keuangan, Ministry of Finance Republic of Indonesia.

\section{REFERENCES}

1. Wijoto H. Memory deficit. In: Buku Ajar Ilmu Penyakit Saraf. Surabaya: Airlangga University Press; 2011.

2. Susanto Y, Djojosoewarno P, Rosnaeni R. Effect of light exercise towards short term memory in adult women. J Knowl Manag 2009;8:144-50.

3. Ardianingsih F. Efek Pemberian Jus Bayam Merah (Amaranthus tricolor Linn.) terhadap Memori Mencit (Mus musculus) yang Diinduksi Timbal Asetat. Thesis Thesis, Universitas Airlangga; 2012.

4. Durazzo TC, Meyerhoff DJ, Nixon SJ. Chronic cigarette smoking: Implications for neurocognition and brain neurobiology. Int J Environ Res Public Health 2010;7:3760-90.

5. Mazzone P, Tierney W, Hossain M, Puvenna V, Janigro D, Cucullo L. Pathophysiological impact of cigarette smoke exposure on the cerebrovascular system with a focus on the blood-brain barrier: Expanding the awareness of smoking toxicity in an underappreciated area. Int J Environ Res Public Health 2010;7:4111-26.

6. Omotoso GO, Babalola FA. Histological changes in the cerebelli of adult wistar rats exposed to cigarette smoke. Niger J Physiol Sci 2014;29:43-6

7. Adeniyi PA, Ogundele OM. Smoke and ethanolic extract of Nicotiana tabacum altered hippocampus histology and behaviour in mice. J Cell Anim Biol 2014;8:34-40.

8. Adeniyi PA, Musa AA. Comparative effects of smoke and ethanolic extract of Nicotiana tabacum on hippocampus and neurobehaviour of mice. Res Pharm Biotechnol 2011;3:68-74.

9. Chen R, Wilson K, Chen Y, Zhang D, Qin X, He M, et al. Association between environmental tobacco smoke exposure and dementia syndromes. BMJ J 2013;70:63-9.

10. Barnes DE, Haight TJ, Mehta KM, Carlson MC, Kuller LH, Tager IB. Secondhand smoke, vascular disease, and dementia incidence: Findings from the cardiovascular health cognition study. Am J Epidemiol 2010;171:292-302.

11. Lister CE, Morrison SC, Kerkhofs NS, Wright KM. The nutritional composition and health benefits of New Zealand tamarillos. Crop Food Res Confid Rep 2005;2005:1-17.

12. Kumalaningsih S. Antioksidan Alami Terong Belanda (Tamarillo). Indonesia: Trubus Agrisarana; 2006. p. 4-11.

13. Kujawski R, Kujawska M, Marcin O, Baraniak J, Sobczak A. Perspectives for gallotannins neuroprotective potential-current experimental evidences. J Med Sci 2016;85:313-8.

14. Yoo KY, Park SY. Terpenoids as potential anti-alzheimer's disease therapeutics. Molecules 2012;17:3524-38.

15. Spencer JP. Flavonoids and brain health: Multiple effects underpinned by common mechanisms. Genes Nutr 2009;4:243-50.

16. Rendeiro C, Rhodes JS, Spencer JP. The mechanisms of action of flavonoids in the brain: Direct versus indirect effects. Neurochem Int 2015;89:126-39. 
17. Kandimalla R, Kalita S, Choudhury B, Kotoky J. Review article a review on anti-diabetic potential of genus Solanum (Solanaceae). J Drug Deliv Ther 2015;5:24-7.

18. Nowinski WL. Introduction to brain anatomy. In: Miller K, editor. Biomechanics of the Brain, Biological and Medical Physics, Biomedical Engineering. New York: Springer; 2011. p. 5-40.

19. Ernst M, Matochik JA, Heishman SJ, Van Horn JD, Jons PH, Henningfield JE, et al. Effect of nicotine on brain activation during performance of a working memory task. Proc Natl Acad Sci U S A 2001;98:4728-33

20. Hu YS, Long N, Pigino G, Brady ST, Lazarov O. Molecular mechanisms of environmental enrichment: Impairments in akt/GSK3 $\beta$, neurotrophin-3 and CREB signaling. PLoS One 2013;8:e64460.
21. Johnston GA. Flavonoid nutraceuticals and ionotropic receptors for the inhibitory neurotransmitter GABA. Neurochem Int 2015;89:120-5

22. Silva AR, Pinheiro AM, Souza CS, Freitas SR, Vasconcellos V, Freire SM, et al. The flavonoid rutin induces astrocyte and microglia activation and regulates TNF-alpha and NO release in primary glial cell cultures. Cell Biol Toxicol 2008;24:75-86.

23. Suk K, Lee H, Kang SS, Cho GJ, Choi WS. Flavonoid baicalein attenuates activation-induced cell death of brain microglia. J Pharmacol Exp Ther 2003;305:638-45.

24. Diniz TC, Silva JC, de Lima-Saraiva SR, Ribeiro FP, Pacheco AG, de Freitas RM, et al. The role of flavonoids on oxidative stress in epilepsy. Oxid Med Cell Longev 2015;2015:171756. 